\title{
Does a temporizing measure of cerebrospinal fluid drainage as the initial procedure alter the surgical outcome in premature infants with post- hemorrhagic hydrocephalus?
}

\author{
Eisha Anne Christian ${ }^{1 *}$, Edward Melamed ${ }^{2}$, Edwin Peck ${ }^{1}$, Mark D Krieger ${ }^{1,2}$, J Gordon McComb ${ }^{1,2}$ \\ From Hydrocephalus 2015 \\ Banff, Canada. 18-21 September 2015
}

\section{Objective}

It has been speculated whether the insertion of a temporary device to control hydrocephalus secondary to intraventricular hemorrhage (IVH) in the preterm neonate with removal of the debris caused by such a hemorrhage, can reduce subsequent complications following insertion of a permanent cerebrospinal fluid (CSF) diverting shunt. This retrospective review is directed at examining this speculation.

\section{Methods}

A retrospective review of the medical records of all premature infants surgically treated for post-hemorrhagic hydrocephalus (PHH) between 1997 and 2012 at our institution was undertaken.

\section{Results}

Over 14 years, 91 preterm infants with PHH were identified. The initial procedure for 50 neonates was the insertion of a ventricular reservoir (VR) that was serially tapped for varying time periods. For the remaining 41 premature infants, a ventriculoperitoneal/atrial shunt (VS) was the first procedure. Patients with a VR as their initial procedure underwent CSF diversion significantly earlier in life than those who had VS as the initial procedure ( 29 vs. 56 days, $\mathrm{p}<0.01)$. Of the infants with a VR as their initial procedure, $5 / 50$ (10\%) did not undergo a subsequent VS. The number of shunt revisions and the rates of loculated hydrocephalus and shunt infection did not statistically differ between the two groups.

\footnotetext{
* Correspondence: echristi@usc.edu

'University of Southern California, Los Angeles, CA, USA

Full list of author information is available at the end of the article
}

\section{Conclusion}

Patients with initial VR insertion received a CSF diversion procedure at a significantly younger age than those who received a permanent shunt as their initial procedure. Otherwise, the outcomes with regards to shunt revisions, loculated hydrocephalus, and shunt infection were not different for the two groups.

\section{Authors' details \\ 'University of Southern California, Los Angeles, CA, USA. ${ }^{2}$ Children's Hospital Los Angeles, CA, USA.}

Published: 18 September 2015

\section{References}

1. Olaya JE, Christian E, Ferman D, Luc Q, Sanger T, Krieger M, Liker M: Deep Brain Stimulation in Children and Young Adults with Secondary Dystonia: The Children's Hospital Los Angeles Experience. Neurosurgical Focus 2013, 35(5):E7.

2. Karas PJ, Mikell CB, Christian E, Liker M, Sheth S: Deep Brain Stimulation: a mechanistic and clinical update. Neurosurgical Focus 2013, 35(5):E1

3. Christian E, Yu C, Apuzzo ML: Focused Ultrasound: Relevant History and Prospects for the Addition of Mechanical Energy to the Neurosurgical Armamentarium. World Neurosurgery 2014, 82(3-4):354.

4. Christian E, Harris B, Wrobel B, Zada G: Endoscopic endonasal transsphenoidal surgery: implementation of an operative and perioperative checklist. Neurosurgical Focus 2014, 37(4):E1.

5. Christian E, Huang C, Yen C, Acosta FA, Chen TC, Liu JC, Spoonamore M, Wang JC, Hsieh PC: A modified Gaines approach for lumbosacral traumatic spondyloptosis: A historical review and case illustration. J Spine 2014, 3(4).

6. Christian E, Imahiyerobo T, Nallapa S, Urata M, McComb JG, Krieger M: Intracranial hypertension after surgical correction for craniosynostosis: a systematic review. Neurosurgical Focus 2015.

\section{doi:10.1186/2045-8118-12-S1-P8}

Cite this article as: Christian et al:: Does a temporizing measure of cerebrospinal fluid drainage as the initial procedure alter the surgical outcome in premature infants with post-hemorrhagic hydrocephalus? Fluids and Barriers of the CNS 2015 12(Suppl 1):P8. 